\title{
PECULARITIES OF GAS ANALYSIS IN Al AND Mg POWDERS
}

\section{P. Oslanec, M. Škrobian}

\begin{abstract}
A new inert gas fusion method has been developed for determining oxygen and nitrogen in $\mathrm{Al}$ and $\mathrm{Mg}$ powders. The approach, the methods and some results are discussed. Dissociation of AlSilOMg powder, 99.9 $\% \mathrm{Mg}$ powder, $\mathrm{Mg}$ alloy powder and $\mathrm{MgO}$ p.a. are presented.

Keywords: oxygen determination, nitrogen determination, aluminium powder, magnesium powder, $\mathrm{MgO}$, inert gas fusion
\end{abstract}

\section{INTRODUCTION}

There are several groups of methods used for oxygen and nitrogen determination. Interaction of oxygen and nitrogen carrier material and various kinds of energy beams (Xray, electron, laser, etc.) has been showing a good results, acceptance in scientific communities. Such a method is robust for some types of chemical analyses, but they are lacking the acceptable uncertainty for these gas measurements [1]. Surface layers profiling methods are also used in oxygen and nitrogen determination, but these methods are used only for surface layers [2]. The inert gas fusion analysis (hot extraction method) is a procedure used for the direct oxygen and nitrogen determination. The oxygen determination is done with a nondispersive infrared absorption method and nitrogen with a thermal conductivity measurement. This is obtained primarily with high sensitivity and purpose, detectors and methods that can easily be calibrated with various sets of standards (Table 3 ). Oxygen is one of the most important impurities that can affect various properties of the material (mechanical, electrical, thermal, etc.) [3]. The oxide volume is always connected with the processing route, powder surface area, humidity residuals (residuals of chemical processes with humidity) on the surface, and storage conditions of the powder [2]. materials are:

Main problems connected to this type of analysis regarding $\mathrm{Al}$ and $\mathrm{Mg}$ powder

- high stability of $\mathrm{Al}$ and $\mathrm{Mg}$ oxides at high temperatures, caused by the high affinity of metals to oxygen

- highly unstable sample volume of magnesium powders, caused by the high tension of magnesium vapors $\mathrm{Al}$ and $\mathrm{Mg}$.

$\mathrm{Al}_{2} \mathrm{O}_{3}\left(\alpha-\mathrm{Al}_{2} \mathrm{O}_{3}\right)$ and $\mathrm{MgO}$ are characteristic oxides in industrial grade powders of

The aim of this paper is to verify the complete decomposition of oxides within powder samples and to specify the methodology for measuring such types of samples. In the case of analysis of metals with high vapour pressures (e.g. $\mathrm{Mg}$ ), the methodology is not available and therefore the objective is to design and test such methodology. 


\section{Oxygen analysis in metal powders with high affinity to oxygen}

The $\mathrm{Al}_{2} \mathrm{O}_{3}$ has high affinity to oxygen and withstands reduction conditions and temperatures up to $1500^{\circ} \mathrm{C}$. The analysis has to be performed at a high temperature with the presence of carbon. The dissociation is following the carbothermal reduction,

$$
\mathrm{Al}_{2} \mathrm{O}_{3}+3 \mathrm{C}=2 \mathrm{Al}(\mathrm{l})+3 \mathrm{CO}(\mathrm{g})
$$

where carbon monoxide in gaseous form is a product of such a reaction. The standard Gibbs free energy, equilibrium constant of reaction and $\mathrm{CO}$ equilibrium partial pressure, between $1500-2500^{\circ} \mathrm{C}$, are shown in Table 1 . If we are going to consider the activities of solid and liquid (molten) phases as unitary, then the equilibrium constant equals to the third power of the carbon monoxide partial pressure.

Tab.1. Thermodynamic parameters of the reaction (1).

\begin{tabular}{|l|l|l|l|l|l|l|}
\hline Temperature $\left[{ }^{\circ} \mathrm{C}\right]$ & 1500 & 1700 & 1900 & 2100 & 2300 & 2500 \\
\hline$\Delta \mathrm{G}^{\circ}, \mathrm{kJ}$ & 305,673 & 190,309 & 75,745 & $-35,833$ & $-138,728$ & $-240,123$ \\
\hline $\mathrm{K},-$ & $9,875.10^{-10}$ & $9,15.10^{-6}$ & $1,511.10^{-2}$ & 6,149 & $6,552.10^{2}$ & $3,337.10^{4}$ \\
\hline $\mathrm{p}(\mathrm{CO}),[$ bar $]$ & $9,958.10-4$ & $2,092.10^{-2}$ & $2,472.10^{-1}$ & 1,832 & 8,685 & 32,190 \\
\hline
\end{tabular}

Considering the thermodynamic parameters of the reaction, we can assume that $1500^{\circ} \mathrm{C}$ should be sufficient for dissociation of oxide in the reaction chamber. Optimization of measuring parameters for dissociation showed that we need to use $1800^{\circ} \mathrm{C}$, to improve measurement times.

\section{Oxygen analysis in metal powders with high affinity to oxygen and high vapour pressure}

$\mathrm{MgO}$ reduction follows reaction (2)

$$
M g O+C=M g(l, g)+C O(g)
$$

where magnesium is in a form of liquid and gas, because of its low boiling point $\left(1107^{\circ} \mathrm{C}\right)$. The standard Gibbs free energy, equilibrium constant of the reaction and $\mathrm{CO}$ equilibrium partial pressure, between $1500-2500^{\circ} \mathrm{C}$, are given in Table 2 . At temperatures over $1500^{\circ} \mathrm{C}$ magnesium is present only in the form of gas and the equilibrium constant equals to

$$
K a=\frac{p_{C O} \cdot p_{M g(g)}}{a_{M g O} \cdot a_{C}}
$$

where $\mathrm{p}_{\mathrm{CO}}$ refers to partial pressure of $\mathrm{CO}, \mathrm{p}_{\mathrm{Mg}(\mathrm{g})}$ is the partial pressure of magnesium in gaseous form, $\mathrm{a}_{\mathrm{MgO}}$ is the activity of magnesium oxide and $\mathrm{a}_{\mathrm{C}}$ is the activity of carbon. 
Tab.2. Thermodynamic parameters of the reaction (2).

\begin{tabular}{|l|l|l|l|l|l|l|}
\hline Temperature $\left[{ }^{\circ} \mathrm{C}\right]$ & 1500 & 1700 & 1900 & 2100 & 2300 & 2500 \\
\hline$\Delta \mathrm{G}^{\circ}, \mathrm{kJ}$ & 23,827 & 10,029 & $-3,654$ & $-17,227$ & $-30,694$ & $-44,057$ \\
\hline $\mathrm{K},-$ & $1,156.10^{-3}$ & $7,746.10^{-2}$ & 2,331 & $3,861.10^{1}$ & $4,048.10^{2}$ & $2,967.10^{3}$ \\
\hline $\mathrm{p}(\mathrm{CO}),[\mathrm{bar}]$ & $3,400.10^{-2}$ & $2,783.10^{-1}$ & 1,527 & 6,214 & $2,012.10^{1}$ & $5,447.10^{1}$ \\
\hline
\end{tabular}

Considering the thermodynamics of the reaction, we can assume that $1500^{\circ} \mathrm{C}$ is sufficient for dissociation of oxide in the reaction chamber. The main problem of the analysis is magnesium evaporation behaviour at equilibrium conditions. Vapour pressure of magnesium at $1500^{\circ} \mathrm{C}$ is 12,8 bar, 41,7 bar at $1800^{\circ} \mathrm{C}$. These conditions can lead to an uncontrolled behaviour of magnesium melt in the reaction chamber and affect the measuring method.

To suppress magnesium evaporation effects lowering the magnesium activity is needed. Several authors $[4,5]$ are referring to a magnesium activity drop in binary $\mathrm{Ni}-\mathrm{Mg}$ and ternary liquid $\mathrm{Cu}-\mathrm{Mg}-\mathrm{Ni}$ alloys. Activity of magnesium vapours in such alloys can be decreased 100 times in comparison to the activity of magnesium vapour over free melt. In this case, the $\mathrm{CO}$ dominates in carrier gas and the effect of magnesium vapours can be negligible.

\section{EXPERIMENTAL}

The experimental part of this work was done with the Bruker Galileo G8 analysis device. Gas analysis takes place in the analysis chamber, where the graphite crucible is heated up to $1800^{\circ} \mathrm{C}$. In this chamber the dissociation of oxides is achieved.

To check the complete decomposition of oxides in the Al powder, we choose the AlSi10Mg aluminium powder with 3 different powder size distributions. Powders are prepared with a gas atomization process with the company IMR Metal powder technologies $\mathrm{GmbH}$, with special attention given to the post-process contamination during the production route. Powders with median size $\mathrm{d}_{50}$ of $14.6 \mu \mathrm{m}, 41.2 \mu \mathrm{m}$ and $86.3 \mu \mathrm{m}$ were used for gas measurements.

To create a new measurement method and check the possibility of measuring $\mathrm{O}$ and $\mathrm{N}$ in magnesium powders we have chosen to decompose pure $\mathrm{MgO}$ to confirm stoichiometric content of $\mathrm{O}$. The prepared method was used to measure $\mathrm{O}$ composition in 2 types of Mg powders (MA and MB). Powder MA is a high purity magnesium powder $(99,9$ $\%$ of $\mathrm{Mg}$ ) and powder $\mathrm{MB}$ is alloyed magnesium powder (WE43 grade powder). MA is a powder with median size $\mathrm{d}_{50}$ of $15 \mu \mathrm{m}$ and $\mathrm{MB}$ has $\mathrm{d}_{50}$ of $40 \mu \mathrm{m}$.

Powder materials are not suitable for loading directly into a measuring device, because there is a possibility of losing some mass of the sample during the measuring operation. It is necessary to use a capsule to put the powder in, and only after that the sample is loaded into the device. The capsule serves also as a melting flux material. Melt created during the sample heating procedure helps the heat to spread into the sample. This can accelerate the decomposition. As mentioned above, magnesium high vapour pressure and evaporation behaviour affects the measuring method. When the magnesium powder is measured without any extra additives, magnesium deposits can be found in colder parts of the reaction chamber (and a glass wool filter), because the magnesium vapours are carried with $\mathrm{CO}$ in carrier gas and condensate in the form of magnesium crystals (Figure 1). These deposits can react with the $\mathrm{CO}$ flow in carrier gas, convert to $\mathrm{MgO}$ and affect resulting $\mathrm{O}$ values. Magnesium powder samples are put into a Ni capsule and compressed with pliers to 
expel as much air as possible. A nickel capsule is capable of shielding the magnesium sample from convective and radiative heat during the placement of the sample into reactive melt.

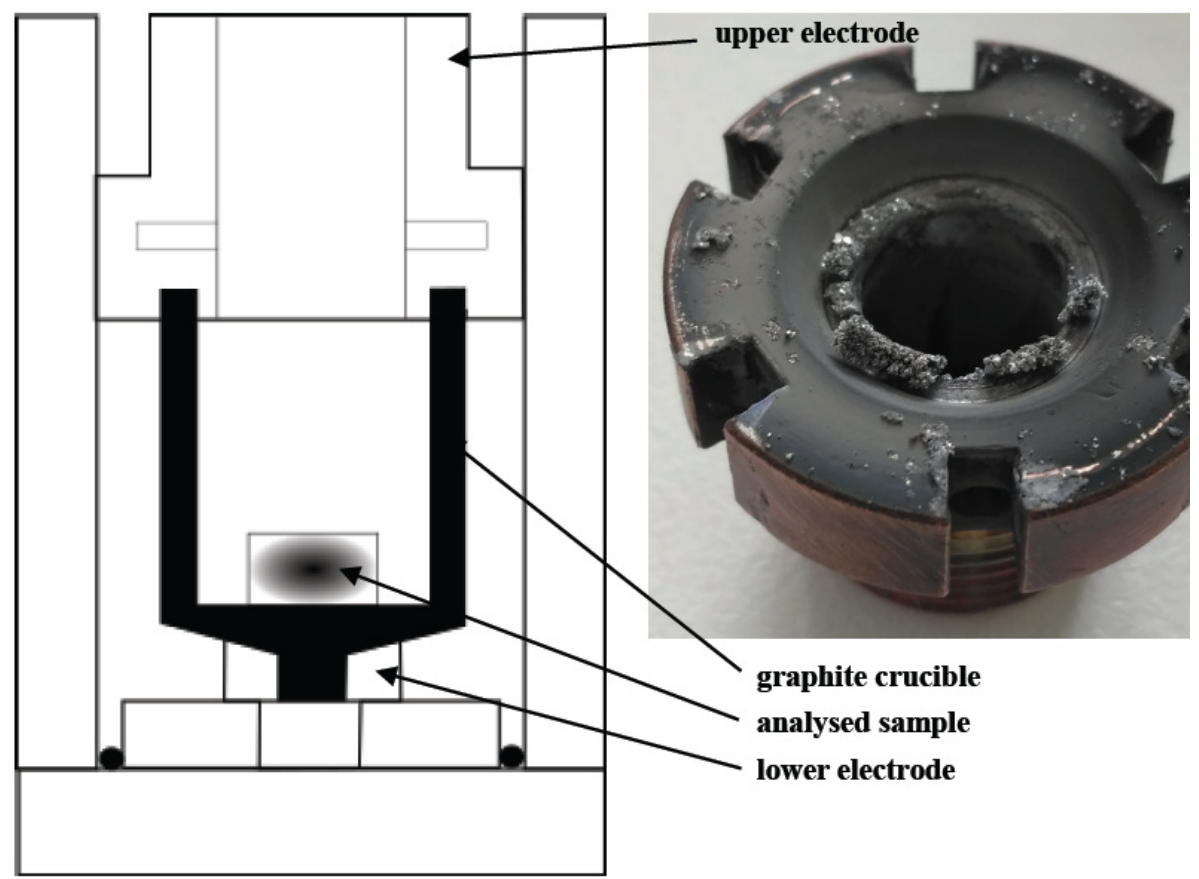

Fig.1. Reaction chamber and magnesium deposits on upper electrode

The aluminium powder is also put inside a Ni capsule and compressed with pliers to expel as much air as possible.

Dissociation of oxides takes place in the reactive medium in the graphite crucible. This medium varies with the analysed material. For aluminium powder the reactive medium is $\mathrm{Ni}$ melt with admixture of a graphite powder. For magnesium powder the reactive medium is melt prepared from a saturated mixture of powder graphite, $\mathrm{Cu}$ metal and $\mathrm{Ni}$ flux. $\mathrm{Cu}$ to $\mathrm{Ni}$ ratios vary, but values go around $\mathrm{x}_{\mathrm{Cu}} / \mathrm{x}_{\mathrm{Ni}}=2$. Oxygen free purity of reactive melt and graphite crucible is achieved with a preheating cycle up to $3000{ }^{\circ} \mathrm{C}$.

Signals resulting from the graphite crucible, Ni capsule, graphite powder and $\mathrm{Cu}$ metal are taken into account as blank signals. Powder with a wide range of particle size distributions needs a wide range $\mathrm{O}$ concentration calibration. There are several standards available from various types of materials (Table 3). To minimize errors associated with the weighing, standards with weight characteristics close to the analysed sample should be used.

Tab.3. A set of standards for ON determination method for wide range of $\mathrm{O}$ concentrations.

\begin{tabular}{|l|l|l|}
\hline & O [wt.\%] & N [wt.\%] \\
\hline Standard 1 & $1.09 \pm 0.02$ & $0.0067 \pm 0.0005$ \\
\hline Standard 2 & $0.104 \pm 0.0061$ & $0.0064 \pm 0.0009$ \\
\hline Standard 3 & $0.0081 \pm 0.009$ & $0.0213 \pm 0.0018$ \\
\hline Standard 4 & & $1.89 \pm 0.06$ \\
\hline
\end{tabular}




\section{RESULTS AND DISCUSSION}

\section{Measuring oxygen and nitrogen in Al powders}

The measurement of 3 different AlSil0Mg powders (powder A, B, C) showed oxygen concentrations up to $850 \mathrm{ppm}$ (powder A). Powder C has low oxygen content with high standard deviation of measured values. A good correlation between the size characteristics of the powder and oxide concentration is seen from the measured data (Table 4). There are several authors reporting different oxygen content on different chemistries of aluminium powders $[2,6,7]$. Low oxygen content in our samples is related to the processing treatment in the powder production route. According to the measurement results, there is no nitrogen introduced into $\mathrm{Al}$ powder in the production route.

We considered the powder A and C as our ,standards" and prepared mixtures with $0.27 / 0.5 / 0.75$ mass ratios of powder $\mathrm{A}$ and used them as control samples to check the full decomposition of oxides in the sample. In the case when the $\mathrm{Al}_{2} \mathrm{O}_{3}$ is not completely decomposed, or the accuracy of the analysis significantly differs from the measured oxygen content, the results of the analysis will substantially differ from the expected values calculated as the weighted value of the individual standards.

In Figure 2, one can see a difference in the linear regression of data between the theoretical mixtures (red line) and the measured ones (black line). Based on this analysis, it appears that the oxygen content of Standard A and Stage $\mathrm{C}$ is underestimated. A measurement of oxygen content in the mixture was performed 3 weeks after the measurement of standards. Oxygen content has probably increased as a result of the storage conditions.

Tab.4. Powder size and surface characteristics, powder oxygen concentration

\begin{tabular}{|l|l|l|l|l|}
\hline Powder & Powder size & $\mathrm{d}_{50}[\mu \mathrm{m}]$ & Specific surface $\left[\mathrm{m}^{2} \cdot \mathrm{kg}^{-1}\right]$ & $\mathrm{O}[\mathrm{ppm}]$ \\
\hline A & $<20 \mu \mathrm{m}$ & 14.6 & 483.9 & $760.1 \pm 71.2$ \\
\hline B & $>20 \mu \mathrm{m}<63 \mu \mathrm{m}$ & 41.2 & 155.9 & $321.9 \pm 78.9$ \\
\hline C & $>63 \mu \mathrm{m}<106 \mu \mathrm{m}$ & 86.3 & 71.9 & $88.1 \pm 55.3$ \\
\hline
\end{tabular}

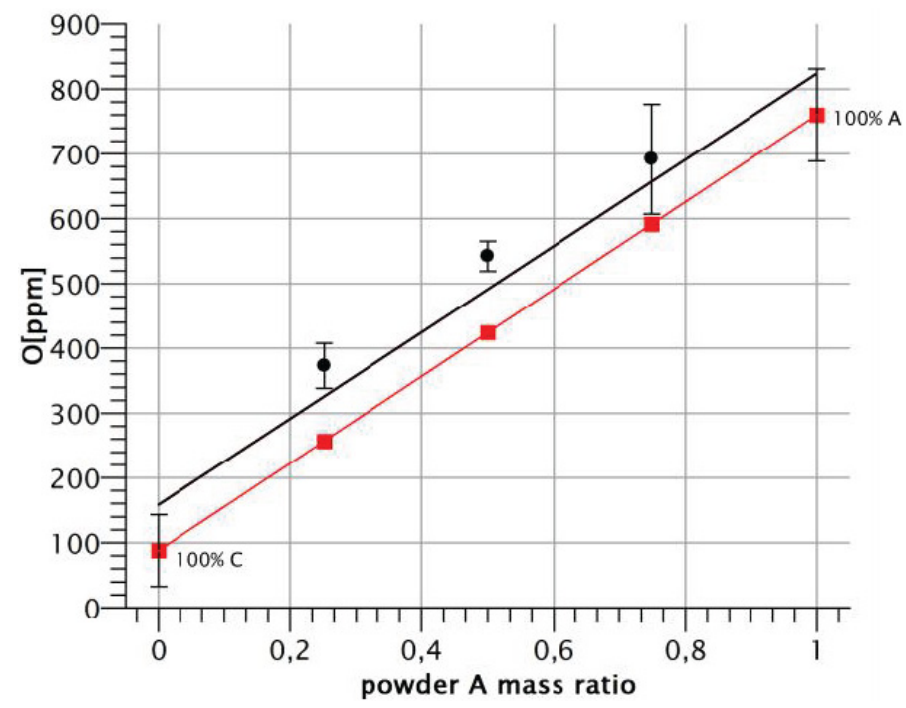

Fig.2. Powders A and C mixture oxygen concentrations. 


\section{Measuring oxygen and nitrogen in Mg powders}

A new method for obtaining the $\mathrm{O}$ concentration in magnesium powders was verified with the decomposition of $\mathrm{MgO}$ (p.a. grade). The $\mathrm{MgO}$ was heated to $600^{\circ} \mathrm{C}$ to remove any traces of water as $\mathrm{Mg}(\mathrm{OH})_{2}$. Samples of $0,4 \mathrm{Mg}$ were used for measurement. Decomposition temperature was $1800^{\circ} \mathrm{C}$. Measured value for $\mathrm{O}$ concentration was 379035 $\pm 29367 \mathrm{ppm}$. The calculated value of $\mathrm{O}$ concentration from $\mathrm{MgO}$ stoichiometry is 396953 ppm. This method shows a good agreement with the calculated value. If we consider the measured value as the true one, the relative error of measurement is $4.5 \%$. With respect to this result, we measured powders MA and MB.

Oxygen concentrations of magnesium powders (Table 5) show higher values than aluminium powders. According to the measurement results there is no nitrogen introduced into $\mathrm{Mg}$ powder in the processing route. Magnesium as a more reactive material tends to create a passivation layer that is prone to humidity and creates hydroxides. The compact oxide layer has created ridges and because of different thermal expansion coefficients and interlayer strains, these ridges are growing into nodules. These new uncovering surfaces and diffusion paths in the volume of existing oxides are ways for the creation of new oxides [8]. This phenomenon is the main driving force for higher oxide concentration when comparing aluminium powders with the similar median size.

Tab.5. Measured $\mathrm{O}$ concentration in magnesium powders

\begin{tabular}{|c|c|c|}
\hline Powder & $\mathrm{d}_{50}[\mu \mathrm{m}]$ & O [ppm] \\
\hline MA & 15 & $1639.7 \pm 422.1$ \\
\hline MB & 40 & $758.7 \pm 336.1$ \\
\hline
\end{tabular}

\section{CONCLUSION}

Both methods show results which are comparable with the level of uncertainties of other authors working with the hot extraction method elsewhere $[1,9,10]$. The lack of comparison data on these materials requires more precise systematic work. To achieve a good practice, repeatable measurements and smaller standard deviations, methods need to be refined and tested with various types of $\mathrm{Al}$ and $\mathrm{Mg}$ powder materials.

\section{Acknowledgement}

Some results were acquired using infrastructure built during the projects ITMS 26220220034

\section{REFERENCES}

[1] Kipphardt, H., Dudzus, T., Meier, KA., Recknagel, S., Hedrich, M., Matschat, R.: Materials transaction, vol. 43, 2002, no. 2, p. 98

[2] Flumerfelt, JF.: Aluminum powder metallurgy processing, Digital repository, 20.6.2017

[3] Balog, M., Hu, T., Krizik, P., Riglos, MVC., Saller, BD., Yang, H., Schoenung, JM., Lavernia, EJ.: Materials Science and Engineering A, vol. 648, 2015, p. 61, DOI: 10.1016/j.msea.2015.09.037

[4] Gnanasekaran, T., Ipser, H.: Journal of Non-Crystalline Solids, vol. 156-158, 1993, p. 384

[5] Mohammad Mezbahul-Islam, Ahmad Omar Mostafa, Mamoun Medraj Hindawi: Journal of Materials, vol. 2014, Article ID 704283 http://dx.doi.org/10.1155/2014/704283 
[6] Pieczonka, T., Schubert, T., Baunack, S.: Sintering Behaviour of Aluminium in Different Atmospheres

[7] Chua, AS., Brochu, M., Bishop, DP.: Spark plasma sintering of prealloyed aluminium powders

[8] Czerwinski, F.: JOM, May, 2004

[9] Krasovskii, PV.: Inorganic materials, vol. 50, 2014, p.1480, DOI: $10.1134 / \mathrm{S} 0020168514150059$

[10] Colombo, A.: Analytica Chimica Acta, vol. 81, 1976, p. 397 